\title{
Fostering Online Student Participation
}

\author{
Regina Bento, (E-mail: rbento@ubalt.edu), University of Baltimore \\ Barry Brownstein, (E-amil: bbrownstein@ubalt.edu), University of Baltimore \\ Cindy Schuster, University of Baltimore \\ Susan Zacur, (E-mail: szacur@ubalt.edu), University of Baltimore
}

\begin{abstract}
The challenges of teaching online include encouraging student participation. Although many instructors would like to increase participation in their online courses, there is no established body of knowledge on the various forms such participation may take, or how it should be evaluated. This paper outlines two major pedagogical approaches, the transmission model and the transformation model and suggests that the transformation model is uniquely suited for online learning. Once the preferred model is established, guidance in ways to foster online student participation is provided.
\end{abstract}

\section{INTRODUCTION}

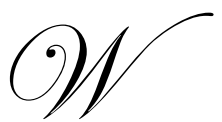

ith the increasing popularity of student-centered and constructivist approaches to education, student participation in class discussions is being considered not just something "nice to have", but an essential part of the teaching and learning process. As we move from traditional to virtual classrooms, the challenge of understanding and nurturing such participation becomes even greater. This paper contributes to faculty understanding of ways to foster online participation.

For the purposes of our discussion, web-based education will be seen as a special case of Distance Education. DE is "planned learning that normally occurs in a different place from teaching and as a result requires special techniques of course design, special instructional techniques, special methods of communication by electronic and other technology, as well as special organizational and administrative arrangements." (Moore \& Kearsley, 1996, p. 2)

Distance Education is here to stay. Currently, over 50 percent of U.S. colleges and universities are offering DE courses, and over 2 million students are taking them. It is estimated that almost 90 percent of U.S. colleges and universities will be offering DE courses, and by 2006 almost 5 million students are projected to be taking them ( Alavi \& Leidner, 2001; Fornaciari, 2002; Symonds, 2001).

This growth in distance education, however, has not been accompanied by a proportional growth in the understanding of its pedagogical implications ( Bento \& Schuster, 2003; Gallini, 2001; Shedletsky \& Aitken, 2001). This gap is particularly glaring in terms of fully exploring the interactive potential of one special form of DE, webbased education. One of the main challenges in web-based education is to understand and encourage student participation. Although many online instructors profess to value, and industriously attempt to grade online participation, there is no established body of knowledge on the various forms such participation may take, or how it should be measured. This paper examines relevant educational paradigms that consider the roll of participation in the teaching and learning process and discusses the pedagogical issues involved.

\section{TWO TEACHING PARADIGMS}

Distance education can be approached from two main paradigms: transmission and transformation (Berge 1999; Berge, 2001). In the transmission paradigm, "content and knowledge determined by someone else is transmitted to the learner (Berge, 1999 p. 19). In the transformation paradigm, "a learner transforms information, generates hypotheses, and makes decisions about the knowledge he or she is constructing or socially constructing through interpersonal communication with others." (ibid, p. 19). Each of these will be discussed in turn. 


\section{The Transmission Paradigm}

The basic assumption of the Transmission paradigm is that there is a body of fixed information, which can be passed on to students. In this instructor-centered approach, the instructor selects the content and the teaching methods that will best "push" such preconceived knowledge to the students, from whom a specific outcome is expected. In the transmission paradigm, the main value of student participation is to provide evidence of whether the student has correctly "absorbed" the content that the expert instructor has attempted to transmit. The intellectual roots of the Transmission paradigm can be found in positivism (transmission of knowledge from an expert to a novice) and behaviorism (new behavioral patterns are introduced and repeated until they become automatic).

Although the transmission model may be appropriate for some basic technical courses, at the upper division university level, there would be few courses which this approach would be optimal. The transmission model is built on a limited perspective on the nature of knowledge. Nobel laureate Friedrich Hayek (1945) explained that not all knowledge is scientific or expert in nature, thus making it impossible for any system to be expertly designed from the top down. Hayek writes:

"....there is beyond question a body of very important but unorganized knowledge which can not possibly be classified scientific...It is with respect to this (unorganized knowledge) that every individual has some advantage over others because he possess unique information of which beneficial use might be made." (ibid, p. 521)

In other words the "sage on the stage" expertly transmitting knowledge fails to take advantage of important knowledge that is distributed throughout the class. This is particularly true in online university courses where many of the students may be working and/or more mature adults.

The assumptions of the transmission model have also been questioned by authors such as Paulo Freire (1970), who criticizes it as a "banking model" of education, where an instructor deposits information into students. A "sage on the stage" relates to students via a hierarchal model which makes liberal use of power and control. The "sage" has in mind an outcome and thinks of how to get one to do what I think one should do. There are good reasons why the transmission or "sage on the stage" model is inappropriate to web based education. The most obvious reason why is that there is no "stage" in web-based education. Professors who attempt to duplicate the classroom environment in a web-based environment quickly find out that this chokes off participation. In the transmission model, the professor remains the focus of attention and everything is funneled through and to the professor. We have seen web-based classes which operated under the "transmission" model where students had no idea who their classmates were. Such classes were basically directed self-study courses where assignments were handed into the professor. Trying to duplicate online what we have done in the classroom misses the opportunities and the advantages of the web environment.

\section{The Transformation Paradigm}

In the transmission and transformation models, the professors have much different roles. In the transmission model, the professor is a "sage on the stage" while in the transformation model the professor is a "guide on the side." Online courses lend themselves to the transformation or "guide on the side" model. Collison, Elbaum, Haavind, and Tinker (2000, p. 8) succinctly discuss the advantages of the "guide on the side" model:

"As participants react to content, share challenges, teach each other, and learn tangibly by putting into words (discussion postings) their own understandings and clarifications of assumptions, they experiment with and eventually take ownership of new skills and ideas. All along, the "guide on the side" serves to focus and deepen the dialogue without getting in the way of participants development of their own expertise."

McMaster (1997, p. 96) observes "we tend to apply the engineering approach to information and learning...We think that by giving information to people, whether in a classroom or manual, we have given them knowledge." Once however that you understand that the true nature of knowledge is "always and only implicit and self-generated" (McMaster, 1997, p. 96) then you understand that knowledge is not easily transferred by the "sage on 
the stage." To turn information into knowledge a student has to make personal meaning of the information. McMaster (1997, p. 95) points that "intelligence comes into being and creates meaning from dialogue, conversations, and community...Humans remember stories and are guided into action by them."

Web based learning is uniquely constructed to foster dialogue where stories and interpretations can be shared. The Transformation paradigm focuses on the activities of the learners, and how they actively participate in the construction of knowledge. In this learner-centered approach, multiple perspectives and flexible methods make it possible for students to adapt, process and filter content into their own logical frameworks, resulting in outcomes that may not be thoroughly predictable. Instead of "learning" a discipline exactly as it is known by others, students develop personal ways of framing problems within the broader framework of the language and concepts of that discipline.

In an online context, learning takes place in an iterative process where students consider the points made by classmates and inquire and reflect on them. When students inquire and reflect they set an intention of gaining additional insight and perspective. They ask generative questions that help take the class beyond their current understanding. They become aware of assumptions that they are making about a classmates' postings. By approaching another student's work with a "beginner's mind" - and by not assuming that they are sure what the other students are thinking - they allow themselves and their classmates to make fresh starts with the material and see things differently. This sets the conditions for genuine insight, learning and thus growing new knowledge.

The Transformation paradigm has its intellectual roots in constructivism and social constructivism. From a constructivist perspective, "what is thought to be critical is the active participation and reflection by the learner, while recognizing the flexible and dynamic nature of knowledge" (Berge, 1999, p. 21). This emphasis on the dynamic nature of knowledge is also present in social constructivism, where it is combined with an interactionist perspective. Understanding is not a pre-determined outcome, but a process of co-creation where students must explain, elaborate and defend their positions to each other. Interactions involve not only information sharing, but also interpretation, evaluation and criticism of each other's comments and ideas. Students are encouraged to relate readings to their work or personal experience or other reading that they have done as well as uncover, articulate, and challenge assumptions; and propose alternative interpretations based upon reasoned, analytical thinking. When all of this comes together in an online course the results can be astonishing and enter what Pallof and Pratt (2003, p. 36) label as a spiritual dimension where online relationships enter great depth and intimacy.

Learning is an emergent phenomenon that takes place through interaction in a community where both the student and professor are learners. Perhaps the professor is a step or two or more ahead of the student, but they are traveling the same road and co-creating an atmosphere where new understandings can emerge. Not surprisingly then, in the Transformation paradigm student participation is at the very center of the individual and collective learning process, as proposed in the constructivism and social constructivism traditions. In this context, student participation is not just a form of testing whether knowledge was transmitted. Rather, social interaction is an intrinsic part of learning. Individual learning does not occur in isolation, but in interaction, contributing to and benefiting from the synergy of a community of learners.

There are good reasons why individual learning cannot occur in isolation. McMaster (1997, p. 78) has pointed out that "knowledge is not static or unchanging; it is emergent, robust and always in a continual process of distribution, integration and reformulation." Thus knowledge "cannot be contained in a single location or individual people." (McMaster, 1997, p. 78) The "guide on the side" is the emerging, preferred paradigm.

\section{NECESSARY CONDITIONS TO USE THE TRANSFORMATION MODEL}

In the "guide on the side" model student and professors are actively co-creating the learning environment. The professor must be comfortable with a real partnership with students where he/she is no longer the "sage" who imparts his wisdom to "empty vessels." When the professor assumes the "sage" part, participation is only done begrudgingly to satisfy course requirements. There is no room for a student to be a fully engaged and wholehearted learner. 
Jim Collins (2001) found that "extreme personal humility" is a characteristic of highly effective leaders. We believe it as also a characteristic of "guides on the sides." The professor must be open to alternative points of view and must see the learning process as ongoing. The professor must be intellectually honest, open to new ideas and respectful of everyone's unique viewpoint. Philosopher Karl Popper (1989, p. 27) observed: "There are no ultimate sources of knowledge. Every source, every suggestion is welcome; and every source, every suggestion is open to critical examination." Respect for students and humility for the limits of their own understanding are essential conditions for a professor who wants to employ the transformation model in online courses.

\section{TYPES OF INTERACTION IN ONLINE EDUCATION}

Online education has been profoundly influenced by the Transformation paradigm and its emphasis on interaction. As a matter of fact, "it seems that everybody in distance education talks about interaction." (Moore, 1996, p.127.) Talking about it, however, is not enough. Moore argues that in order for us to better understand and practice the concept of interaction, we should distinguish three basic types of interaction that must take place in distance education: learner-content, learner-instructor and learner -learner interaction (Moore, 1989, 1996).

Learner-Content interaction has long been the touchstone of education. Knowledge construction happens when the learner interacts with the instructional content in order to accommodate new information into pre-existing cognitive structures, which then results in changes in understanding (Moore, 1996, pp. 128-129).

In distance education, content may be offered to the learner in a variety of ways, such as textual materials in print or electronic formats, radio or TV broadcasts, audio or videotape, computer software and interactive multimedia. But regardless of the level of sophistication in the presentation of content itself, it is only when the student interacts with that content and incorporates it into a personal cognitive structure that learning actually takes place.

This learning is further reinforced through Moore's second type of interaction, Learner-Instructor, which involves activities such as seeking and offering explanations, analogies and examples, and elaborating, discussing and applying content. Those interactions are meant to accomplish multiple objectives: to stimulate student interest and engagement in the learning process; to foster the application of content through skill practice and manipulation of information and ideas; to organize formal and informal ways to test and evaluate the extent to which learning is taking place and, if necessary, develop alternative pedagogical strategies; and to provide support and encouragement to each learner (Moore, 1996, p. 130.).

According to Moore, distance educators often content themselves with helping students achieve those two classic types of interaction, Learner-Content and Learner-Instructor. But for distance education to move beyond the Transmission paradigm and be truly Transformative, a third type of interaction is essential: Learner-Learner. This interaction among learners can take place with students relating directly with each other or in online group settings, with or without the instructor being present in real-time. Learner-Learner interaction is an extremely powerful way of "helping students to think out the content that has been presented and to test it in exchanges with their peers." (Moore, 1996, pp. 131-132.)

Berge highlights the importance of interpersonal interaction in distance education by collapsing Moore's three types of interaction into just two types: interaction with content, and interpersonal interaction. When discussing "Interaction with Content," Berge agrees with Moore: for learning to take place, the student must actively interact and cognitively process the content of the course, not just passively be exposed to it (Berge, 1998, p. 27).

Berge departs from Moore, however, in combining "Learner-Instructor" and "Learner-Learner" Interaction under the single umbrella of "Interpersonal Interaction:" For learning to occur, students must interact with each other and the instructor in order to arrive at shared meaning and to make sense of what they are learning. This social context of learning is crucial for motivation, critical judgment and problem solving (Berge, 1998, p. 28). Interpersonal interaction provides the social context for the mutual construction of understanding and has been demonstrated to play a major role in the learning process (Fulford and Zhang, 1993). Both interaction with content and interpersonal interaction will be discussed below with suggestions for specific actions by professors and students. 


\section{INTERACTION WITH CONTENT}

For students to actively interact with and cognitively process course content, certain things need to happen. First, content must be easily accessible. In an online environment, content must be clearly organized and available in a user-friendly environment. Second, students need to be oriented to the tools they will use to be successful in interacting with course content. First time online students should be directed to the university's online tutorial. An online survey might invite students to indicate technical questions and format issues during the first week of the course. Contact with technical support staff should be encouraged if needed. Third, adequate time for practice interactions during the first week will allow students to develop skills essential for success in their academic work.

Professors can help to insure student success with content by establishing clear expectations. The syllabus can describe the weekly rhythm of the course so that students know how to pace their work on content, posting, and assignments. Guidelines and samples should be provided so that students know what a "good" post looks like, what a discussion thread looks like, and how to engage in online dialogue in a respectful environment that encourages creative thinking.

Other content interaction considerations include the following. Offline materials such as the textbooks, assigned readings, and other media must be readily accessible. Students must see that they will be required to demonstrate use and understanding of these materials in their posts, assignments, and group work on a weekly basis. Lecture notes should be summarized on a few screens with bulleted points. Longer lectures should be provided for download. Before weekly topic discussion begins, the professor can post online notes for the topic(s) to guide students in their discovery of content. At the end of the week, the professor can summarize and place in a larger context the key content points contributed and discovered that week.

\section{INTERPERSONAL INTERACTION}

In a face-to-face course, professors know the importance of establishing rapport through interpersonal interaction with the students during the first class meeting. It is challenging to achieve the same result in an online course. The goal is to create an environment of safety, demonstrate respect for learners, and to earn trust in the professor and other students. Some of the ways to do this include e-mailing a welcome to each student prior to the course and linking to a personal web site that allows students to learn more about your professional life. (Brown, 2003)

An online introduction to the expected interpersonal environment for course participants should include respect, academic honesty, and encouraging interaction with other learners. Students should be required to provide some information about themselves to the entire class. This information can be prompted by the professor and should include at least one relevant query that fits the nature of the course. For example, in a leadership course, students would be asked to identify themselves, tell about their major, work experience, and describe a leadership experience they have had or been a witness to.

In all that the professor does, there must be a highly engaged online presence. The professor should role model the engagement expected of the students. The professor's comments must be complete and timely. Being a "guide on the side" requires feedback to prompt students toward more useful posts but will not require responses to each individual post. The professor's online comments should encourage student interaction, but not get in the way of it. The concept of a learning community will need to be reinforced for several weeks as students learn to trust themselves and their classmates.

To further interpersonal interaction, students could work in pairs and small groups to share ideas first before posting a group message to the larger class. This will foster learning while cutting down on the overall number of posts to be reviewed. Students can be encouraged to bring new material and questions to class dialogue from their own work and academic experience. This will allow wisdom to come from other sources further reinforcing the "guide on the side" role of the professor. 
Interpersonal interaction can extend beyond the class through the use of invited guest speakers. Guests can contribute and then respond to posted questions. (Berge, 1995) Students can be referred to the speaker's preferred websites to expand their understanding of the speaker's contributions.

Finally, a deep respect for the capacity of each student to be successful and to transform him or herself during the course is essential. With "guide on the side" coaching, some of the initially problematical students can develop into star performers. The professor who continues to demonstrate and coach for what is expected in online course behavior will find that the transformation paradigm fosters growth for both students and faculty.

\section{CONCLUSION}

In any course we teach we seek what Fink (2003) calls "significant learning outcomes." Such courses result "in significant changes in the students, changes that continue after the course is over and even after students have graduated." (Fink, p. 7)

We believe the transformation model is uniquely suited for online learning and for fostering significant learning outcomes. It is a major paradigm shift that benefits both professor and student. Although the professor and student are different in role they share a common interest as learners. Mike McMaster (1996, p. 165) writes about a healthy work environment in the following passage, but his words have meaning for a healthy online learning environment that the transformation model fosters:

"When we are passionate about something in life, it is a great challenge to be able to allow ourselves to engage in dialogue with others in ways that allow ourselves to be changed, while at the same time allowing others to engage their passions. It is not our job in life to sell others on our ideas or to get others to believe in something; but perhaps our responsibility lies in being able to express ourselves in ways that contribute to the possibility for all of us."

\section{References}

1. Alavi, M., \& Leidner, D. E. (2001). Research commentary: Technology-mediated learning - A call for greater depth and breadth of research. Information Systems_Research, 12 (1): 1-10.

2. $\quad$ Bento, R. \& Schuster, C. (2003). Participation: The Online Challenge. In A. Aggarwal (Ed.), Web-Based Education: Learning from Experience. Hershey, PA/London, UK: Idea Group Publishing.

3. Berge, Z. L. (2001). The Context of Distance Training. In Zane L. Berge, Ed. Sustaining Distance Training: Integrating learning technologies into the fabric of the enterprise. San Francisco: Jossey Bass pp. 3- 12.

4. Berge, Z. L. (1999). Conceptual Frameworks in Distance Training and Education. In Deborah Schreiber and Zane L. Berge, Eds. Distance Training: How innovative organizations are using technology to maximize learning and meet business objectives. San Francisco: Jossey-Bass. pp.19- 36.

5. Berge, Z. L. (1995). Facilitating Computer Conferencing: Recommendations from the Field. Educational Technology, 35(1): 22-30.

6. Brown, D.G. (2003) Encouraging Good Student Contact. Campus Technology from Syllabus Media Group. http://www.campus-technology.com/print.asp?ID=7630.

7. Collins, J. (2001) Good to Great. New York, New York: Harper Collins

8. Collison, G; Elbaum, B; Haavind, S; Tinker, R. (2000) Facilitating Online Learning Madison, WI: Atwood Publishing

9. $\quad$ Fink, D. (2003) Creating Significant Learning Experiences. San Franciso: Jossey-Bass

10. Fornaciari, C. (2002). Student Personality Types and Enrollments in Distance Education: A Longitudinal Study. Academy of Management Meeting. Denver, CO.

11. Freire, P. (1970). Pedagogy of the oppressed. New York: Herder and Herder.

12. Fulford, C. P. \& Zhang, S. (1993). Perceptions of Interaction: The critical predictor in distance education. The American Journal of Distance Education, 7 (3): 8-21.

13. Gallini, J. K. (2001). A framework for the design of research in technology-mediated learning environments: A sociocultural perspective. Educational Technology, 41(2): 15-21.

14. Hayek, F. (1945) The Use of Knowledge in Society American Economic Review 35 (September): 519-30

15. McMaster, M. (1996) The Intelligence Advantage. Newton, MA.: Butterworth-Heinemann 
16. McMaster, M (1997) The Praxis Equation. Isle of Man: Knowledge Based Development Co.

17. Moore, M. G. (1989). Three Types of Interaction The American Journal of Distance Education, 3 (2): 1-6.

18. Moore, M. G. \& Kearsley, G. (1996). Distance Education: A systems view. Belmont, CA: Wadsworth.

19. Palloff, R \& Pratt, K. (2003) The Virtual Student. San Francisco: Jossey Bass

20. Popper, K. (1989) Conjectures and Refutations. London: Routledge

21. Shedletsky, L. J., \& Aitken, J. E. (2001). The paradoxes of online academic work. Communication Education, 50: 206-217.

22. Symonds, W. (2001,). Giving it the old online try. BusinessWeek, December 3, 2001. pp, 76-80.

\section{Notes}


Notes 